the present theory, although the interpretation offered in terms of $B$ is, of course, not ruled out.

M. C. R. SYMons

Department of Chemistry,

University of Leicester.

Received July $7,1969$.

${ }^{1}$ Symons, M. C. R., J. Phys. Chem., 71, 172 (1967).

${ }^{2}$ de Boer, E., Rec. Trav. Chim., 84, 609 (1965).

${ }^{3}$ Cauters, G. W., de Boer, E., Hendriks, B. M. P., and Klassen, A. A. K., Colloque Ampere XV,243 (1969).

${ }^{4}$ Cauters, G. W., and van Willigen, H., Chem. Phys. Lett., 1, 627 (1968). s McConnell, Ir. M., Hiller, C., Cole, T., and Fessenden, R. W., J. Amer. Chem.
Soc., 82, 766 (1960).

- Gough, T. E., and Symons, M. C. R., Trans. Faraday Soc., 62, 269 (1966).

'Claxton, T. A., Oakes, J., and Symons, M. C. R., Trans. Faraday Soc., 64, 596 (1968).

${ }^{8}$ Hirota, N., J. Amer. Chem. Soc., 89, 32 (1967).

\section{Proton Hyperfine Coupling Constants in Radicals and the Excess Charge- effect}

Considerable controversy ${ }^{1-3}$ has centred around the effect of excess charge on the magnitude of proton coupling constants in such radicals as the cations and anions of aromatic hydrocarbons, benzene, naphthalene and anthracene. Simple theories predict that the coupling constants for cations and corresponding anions should be equal, whereas electron spin resonance results show that the cations always have larger values (Table 1).

Table 1. HYPERFINE PARAMETERS (G) FOR VARIOUS RADICAL CATIONS AND

$\begin{array}{lcccccc} & \begin{array}{c}\text { Anthra- } \\ \text { cene }\end{array} & \begin{array}{c}\text { Anthra- } \\ \text { cene- }\end{array} & \mathrm{BH}_{8}{ }^{-} & \mathrm{CH}_{3} & \mathrm{NH}_{3}{ }^{+} & \mathrm{NaH}^{+} \\ & \mathbf{9 H} & 9 \mathrm{H} & & & & \\ a_{H} & 6.65 & 5 \cdot 56 & 16.5 & 22.5 & 27 & 111.2 \\ \text { Zett } & 1.032 & 0.97 & 0.901 & 1.00 & 1.063 & 1.024 \\ \text { Ref. } & 8 & 8 & 4 & 6 & 6 & 7\end{array}$

The $Z$-cffective values were calculated from the experimental coupling coustants and the values for the neutral radicals. This was taken as the mean values for the anthracene ions, the methyl value for $\mathrm{BH}_{3}{ }^{-}$and $\mathrm{NH}_{3}{ }^{+}$and the value for trapped hydrogen atoms in $\mathrm{BaSO}_{4}$ for $\mathrm{NaH}^{+}$, where allowance was

This trend is greatly magnified in the series of isoelectronic, planar radicals, $\mathrm{BH}_{3}-\mathrm{CH}_{3}$ and $\mathrm{NH}_{3}+$ (ref. 4) (Table I) in which a considerable part of the excess charge must be accommodated by the protons.

This communication proposes a mechanism which seems to accommodate these results without needing to invoke the more sophisticated and possibly questionable ${ }^{5}$ theories previously accepted ${ }^{6}$. The basic concept is simply that the effective radius of the hydrogen $1 s$ atomic orbital should be allowed to change systematically with the excess charge, or, in other terms, that the effective nuclear charge on the proton should be thought of as deviating from unity. This effect is not of great importance for most atoms in molecules, for the fractional change in $Z$ is relatively small and the effect is buffered by the remaining electrons. For protons, however, a small change in the effective nuclear charge $\left(Z_{H}\right)$ can make a large difference to the coupling constant, which will be proportional to $Z_{H^{3}}$. Typical changes in $Z_{H}$, calculated from the observed coupling constants, are included in Table 1 , the reference value of $Z=1$ being arbitrarily taken for $\mathrm{CH}_{3}$ in one series, and the mean of the positive and negative ion values in the other. These changes are, it is felt, physically reasonable, and accommodate the results adequately.

Further evidence for this postulate comes from the species $\mathrm{NaH}^{+}$which has recently been studied in $\gamma$-irradi ated barium sulphate erystals? ${ }^{7}$. Normal trapped hydrogen atoms had an isotropic coupling of $503.9 \mathrm{G}$ in this matrix, whereas $\mathrm{NaH}^{+}$had a proton coupling of $511 \cdot 2 \mathrm{G}$, which is even greater than the gas-phase value. Nevertheless, the spin-density on sodium amounted to at least $5 \cdot 4$ per cent and this was shown to be positive. 'This increase over the expected value can readily be accommodated on the present theory if there is a small increase in the effective nuclear charge on $H$, induced by the neighbouring cation (Table 1).

One prediction that can be drawn from this theory is that the overall hyperfine coupling $(2 a)$ for $\mathrm{H}_{2}-$ may turn out to be very much less than the value of about $500 \mathrm{G}$ normally expected, whereas that of $\mathrm{H}_{2}{ }^{+}$could be several hundred $\mathrm{G}$ greater.

\section{C. R. Symons}

Department of Chemistry,

University of Leicester.

Received Juiy 7, 1969.

1 Jolton, J. R., J. Chem. Phys., 43, 309 (1965).

${ }^{2}$ Colpa, J. P., and Bolton, J. R., Mol. Phys., 6, 273 (1963),

${ }^{3}$ Giacometti, G., Nordlo, P. L., and Pavan, M. V., Theoret. Chim. Bcta, 1, 404 (1963).

4 Symons, M. C. R., and Wardale, H. W., Chem. Commun., 758 (1967).

5 Melchior, M. T., J. Chem. Phys., 50, 511 (1969).

- Ayscough, P. B., Electron Spin Resonance in Chemistry (Methuen, London, 1968).

? Bloom, M. B. D., Eachus, R. S., and Symons, M. C. R., Chem. Commun., 1495 (1968).

${ }^{8}$ Carrington, A., Dravnicks, F., and Symons, M. C. R., J. Chem. Soc., 947 (1959).

\section{O-H .... S Hydrogen Bond in Barium Thiosulphate Monohydrate}

THere is evidence that the sulphur atom is capable of participating in hydrogen bonding systems in solids ${ }^{1-3}$, and numerous diffraction studies suggest that a few different types of this hydrogen bond may exist. Most of these studies are concerned, however, only with interatomic distances and angles involving the donor and acceptor atoms, and the position of the hydrogen atom has been determined in only a small number of cases. The type of $\mathrm{X}-\mathrm{H}$. . . S bond which is best known is that with $\mathrm{X}=\mathrm{N}$, and it has been shown by neutron diffraction that such bonds are present in, for example, both room and low temperature forms of thiourea ${ }^{4}$. The crystallo. chemistry of solid $\mathrm{H}_{2} \mathrm{~S}$ (ref. 5) led Hamilton and Ibers ${ }^{3}$ to believe that the $\mathbf{S}-\mathbf{H}$... S bond also occurs. Finally, the crystal structures of magnesium thiosulphate hexahydrate $^{6}$, barium thiosulphate monohydrate ${ }^{7}$ and $4,4^{\prime}$. dihydroxythiobenzophenone monohydrate ${ }^{8}$, for example, indicate that the $\mathrm{O}-\mathrm{H}$. . S bond may also exist, but these compounds were studied by $\mathrm{X}$-ray methods in which the position of the hydrogen atom could not be determined. Further evidence is required to confirm the existence of the $\mathrm{O}-\mathrm{H} \ldots \mathrm{S}$ bond in solids.

We have carried out a neutron diffraction study of barium thiosulphate monohydrate, $\mathrm{BaS}_{2} \mathrm{O}_{3} \cdot \mathrm{H}_{2} \mathrm{O}$, which crystallizes in the orthorhombic space group $\mathrm{Pben}$, and possesses eight stoichiometric units in a unit cell of dimensions: $a=20 \cdot 07 \pm 0 \cdot 01, b=7 \cdot 19 \pm 0.01$ and $c=7 \cdot 37 \pm$ $0.01 \AA$. The intensities of 615 reflexions in the sphere with $\sin \theta / \lambda$ less than $0.612 \AA^{-1}$ were measured at the Brookhaven National Laboratory High Flux Beam Reactor, using neutrons with a wavelength of $1.050 \AA$. The positional parameters of the non-hydrogen atoms determ. ined by Nardelli and Fava ${ }^{7}$ were used, the positions of the hydrogen atoms were found from an $F_{0}$-map of nuclear density, and the structure was refined by the method of least squares to a value of $R=0.033\left(R_{\text {weighted }}=0.022\right)$.

Our analysis showed that the distance between a sulphur atom of the thiosulphate group and the oxygen atom of the water of crystallization, which according to Nardelli and Fava may represent a hydrogen bond, is $3 \cdot 298 \pm 0 \cdot 004 \AA$. This agrees with the sum of the van der Waals radii for $\mathrm{O}$ and $\mathrm{S}$, but the $\mathrm{H}$... S distance is $2 \cdot 367 \pm 0.004 \AA$, which is $0.68 \AA$ shorter than the corresponding van der Waals distance of $3.05 \AA$. The decisive 